\title{
Midha Rajiv, Zager Eric I: Surgery of peripheral nerves: a case-based approach
}

\section{Thieme Verlag, New York, Stuttgart, 2008, 290 p, 150 figs, Hardcover, $€$ (D) 99.95 CHF 166.00 ISBN 978-0-86577-860-3}

\section{Pierre Kehr}

Received: 15 August 2009 / Accepted: 18 August 2009 / Published online: 10 September 2009

(C) Springer-Verlag 2009

This book is a bit peculiar book, because the author presents various pathologies starting from the study of a clinical case. From the description of the case, the authors proceed first to describe the anatomy, the various etiologies, the clinical characteristics, the differential diagnoses, the complementary examinations, the therapeutic possibilities, and the prognosis.

The presentation at the end of the characteristics and the dangers is astute. On the other hand this iconography regarding surgical techniques is of regrettable quality and needs to be improved.

Nevertheless this book remains didactic and easy to read.

No funds were received in support of this study.

Alain Graftiaux 